\title{
The Role of the Course Website in Improving Access to Educational Materials for Nontraditional Aviation Students
}

\author{
John H. Mott \\ Purdue University
}

\begin{abstract}
Nontraditional students have become the rule rather than the exception in many collegiate aviation programs. These students are often constrained in terms of their ability to devote the same amount of time to their classroom efforts as do their traditional peers. Such constraints may result from scheduling conflicts with work or, to a lesser extent, scheduling conflicts due to the location of classes at multiple and physically-separated campuses. Provision of classroom materials such as course syllabi and lecture notes, through the use of a course website, can help alleviate some of the scheduling concerns that affect nontraditional students. It is instructive to determine the degree to which such a website helps students feel that the convenience of their learning experience has been improved. A study of the use of a course website for this author's aviation classes over a period of two semesters in 2006 and 2007 indicates significant improvement over those courses not employing websites in perceived learning convenience as a result of easier student access to course materials.
\end{abstract}

\section{INTRODUCTION}

While the term "nontraditional student" is not a precise one, some general characteristics that help define the term have been described by Horn (1996). In that study, a nontraditional student was considered to be a student possessing one or more of the following characteristics: the student delayed entry into the postsecondary educational environment, attended on a part-time basis for at least part of the academic year, worked full-time (35 or more hours per week), had at least one dependent other than a spouse, or did not have a high school diploma. Horn defines three specific levels of nontraditionalism among postsecondary students; students at the lowest level, defined as "minimally nontraditional," are those with a single nontraditional characteristic as described above. According to a National Postsecondary Student Aid Study conducted by the National Center for Education Statistics (NCES, 2002), 73\% of all postsecondary undergraduate students during the period 1999 2000 could be described as, at least, minimally nontraditional.

Two of the characteristics used to define nontraditionalism that are likely the least intrusive in terms of the data collection process are those of weekly employment hours and the number of credit hours for which the student is enrolled. Accordingly, these two characteristics were selected for the survey employed in the research methodology. It should be noted that 39 percent of the undergraduates in the NCES study were employed full-time, while 48 percent were enrolled part-time. As a result, it is reasonable to assume that the majority of the students surveyed who are, by definition, minimally nontraditional will meet at least one of these two criteria, and that all of the students who meet either of the criteria are, again by definition, at least minimally nontraditional.

Nontraditional students often have major constraints placed upon the time they have available for class attendance. These constraints may result from being employed full-time, or, in the case of students taking classes at multiple campuses separated by some physical distance, from scheduling conflicts between classes. The NCES study (2002) indicated that the percentages of nontraditional students whose class schedules were limited by their employment ranged from 47.4 percent for minimally nontraditional students to 72.0 percent for highly nontraditional students, those with four or more of the characteristics of nontraditional students described above. A separate study by Dutton and Dutton (2002) suggested that scheduling conflicts between class time and work time were considered "very important" by 55.8 percent of the students taking a computer programming course online at North Carolina State University, and also that conflicts 
between scheduled class periods were perceived to have the same degree of importance by 22.4 percent of those students.

The use of a course website to provide the course description, syllabus, lecture notes, and supplemental material can be considered an intermediate step between a fully-online course offering and no use of online course materials delivery whatsoever. Twigg (2003) refers to a hybrid delivery system as a "supplemental approach" to course redesign, and Rivera, McAlister, and Rice (2002) discuss the use of such a hybrid system in what they term a "webenhanced" course format. Student satisfaction levels measured in that study were somewhat higher with the hybrid format than they were with either a traditional format or with a completely online offering of the same course. Ehrmann (n.d.) suggests that the forms of instructional material used in a hybrid delivery system should be those that most faculty find "easy to create, adapt, and share," and specifically recommends a web-based syllabus, as it affords all students enrolled in the course the ability to view changes to the syllabus at once.

Technical factors such as the speed of the broadband connection used by the student and the availability of the course web server can certainly affect the student's perception of the delivery system, as can the accessibility of an Internet-enabled computer to the student. These factors directly affect the technology acceptance model proposed by Davis, Bagozzi and Warshaw (1989) which addresses the questions of perceived usefulness and perceived ease-ofuse, and were investigated by Selim (2003). Such problems, while they will undoubtedly always be present to some extent, might be minimized by careful attention to the details of the delivery system that is used to provide the required services.

\section{RESEARCH METHODOLOGY}

\section{Purpose of the Study}

The purpose of this study was to gauge the perception of learning convenience held by students enrolled in Aviation Technology courses at the Indianapolis Campus of Purdue University over a two-semester period during which course materials delivery was facilitated with a web-based hybrid delivery system. A course description, objectives, syllabus, lecture notes, and supplemental material were available on a separate web page for each course taught by the author over that period, and those web pages were accessible from a home page to which students were given the corresponding universal resource locator (URL). The individual course pages required both a login identifier and a password for access, and students were given these, as well.

\section{Study Population}

Forty-nine unique students who enrolled in eight different courses over the two-semester period were targeted as the sample population for this study. While it was not guaranteed that the entire sample population would fit the criteria mentioned previously for nontraditional students, questions were asked in the survey itself that would allow the determination of whether the respondents were minimally nontraditional in the sense of Horn (1996) with a reasonable degree of confidence.

\section{Survey Instrument}

A ten-question survey was created to measure the desired parameters. This survey consisted of six questions designed to determine the students' perception of the increase in convenience due to the hybrid delivery system. These questions were provided with standard five-choice Likert scale responses ranging from Strongly Disagree (1) to Strongly Agree (5). The remaining four questions were used for data validation and to determine the degree of nontraditionalism of the study population.

The survey, entitled "Purdue AT Course Website Survey", was created using SurveyMonkey.com, a popular website that provides online survey tools for researchers. The survey was tested on a small population prior to being released to the data collection stage, and feedback from that test was used to refine the instrument to facilitate easier comprehension and improve response accuracy.

\section{Survey Procedure}

An e-mail was sent to current and former students targeted for participation in the twosemester study on April 26, 2007. The e-mail included a URL link to the survey, and 
addressed both the amount of time required to complete the survey (judged to be five minutes or less) and the confidentiality of the responses. The e-mail also included a link that allowed recipients to decline participation in the survey if they so desired.

Three of the 49 e-mails sent (6.1 percent) were returned as undeliverable. One recipient declined to participate in the survey by responding to the corresponding URL. A total of 38 recipients of the invitation e-mail, or 77.6 percent, responded favorably and completed the online survey by May 15, $2007 . \quad$ It was determined that this rate of response was satisfactory for analytical purposes, so no reminder e-mail invitations to participate in the survey were sent. It is recognized that there is a fine line between encouraging survey participation by the sending of multiple invitations and the loss of credibility associated

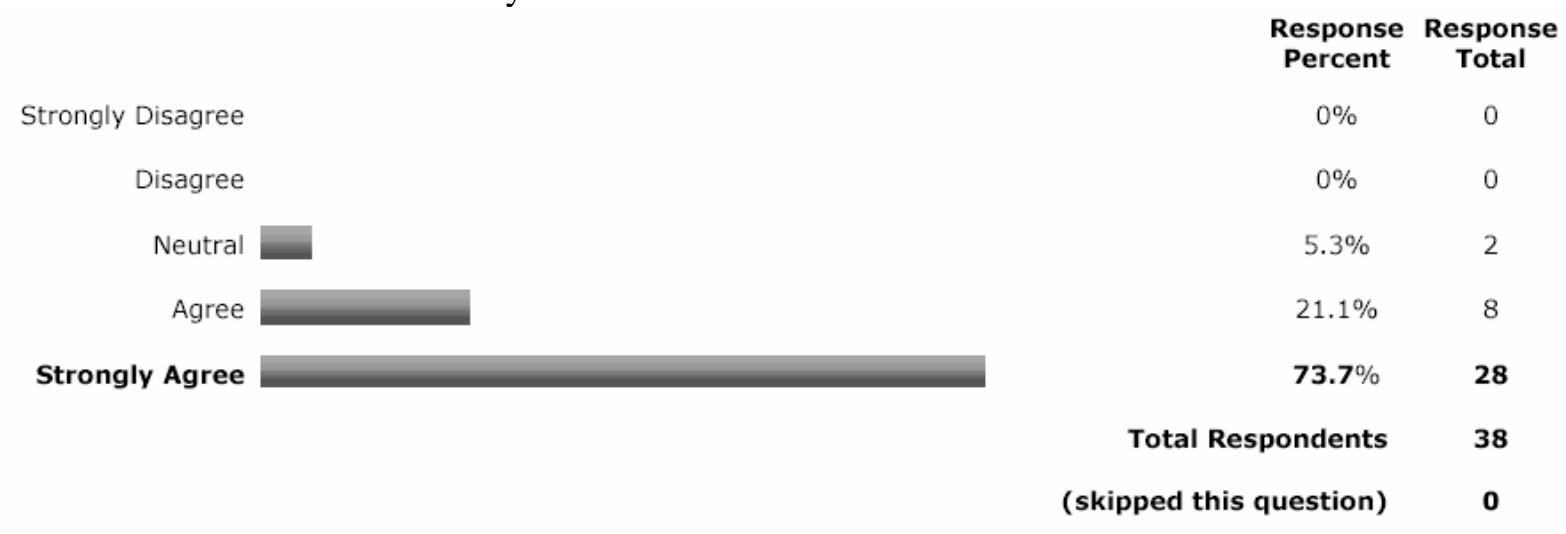

with the sending of unsolicited bulk e-mail, and that recognition tends to cause the researcher to remain on the conservative side in determining an appropriate number of e-mail reminders to send to the target population.

\section{RESULTS OF THE STUDY}

The first two questions of the survey, each providing for a five-choice Likert scale response, allowed the respondents to provide noncomparative opinions on the general convenience of accessing course information (descriptions, objectives and syllabi) and course materials (lecture notes and supplemental material) from the course website. As Figures 1 and 2 show, the majority of survey respondents felt strongly that access to both of these types of data was convenient through the use of the website.

Figure 1. The course website has provided you with a convenient means of accessing course information (description, objectives, and syllabus).

$\begin{array}{rcc} & & \text { Response Response } \\ \text { Total } & \text { Percent } & \text { R } \\ \text { Strongly Disagree } & 0 \% & 0 \\ \text { Disagree } & 0 \% & 0 \\ \text { Neutral } & 0 \% & 0 \\ \text { Agree } & 21.1 \% & 8 \\ \text { Strongly Agree } & \text { Total Respondents } & \mathbf{3 8}\end{array}$

Figure 2. The course website has provided you with a convenient means of accessing course materials (course notes and supplemental materials). 
The next two questions provided data to assist in the determination of the factors responsible for limiting the students' time available for class attendance. The first, Figure 3 , indicates that a plurality of respondents strongly agreed that the course website had allowed them to obtain materials that they would not have otherwise obtained due to their work schedules, while the majority either strongly

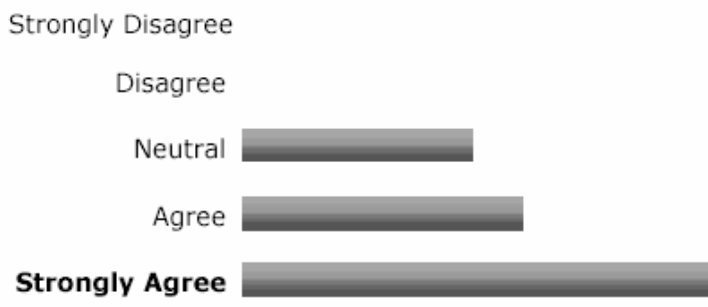

agreed or agreed with that assertion. The second, Figure 4, indicates that, while a large percentage of respondents were neutral on the question of whether the website had allowed them to obtain materials that the scheduling of their other classes would have not allowed them to obtain otherwise, a majority (52.6 percent) either agreed or strongly agreed that this was, indeed, the case.

Figure 3. The course website has allowed you to access materials that your work schedule would have prevented you from otherwise obtaining during a regularly scheduled class period of this course.

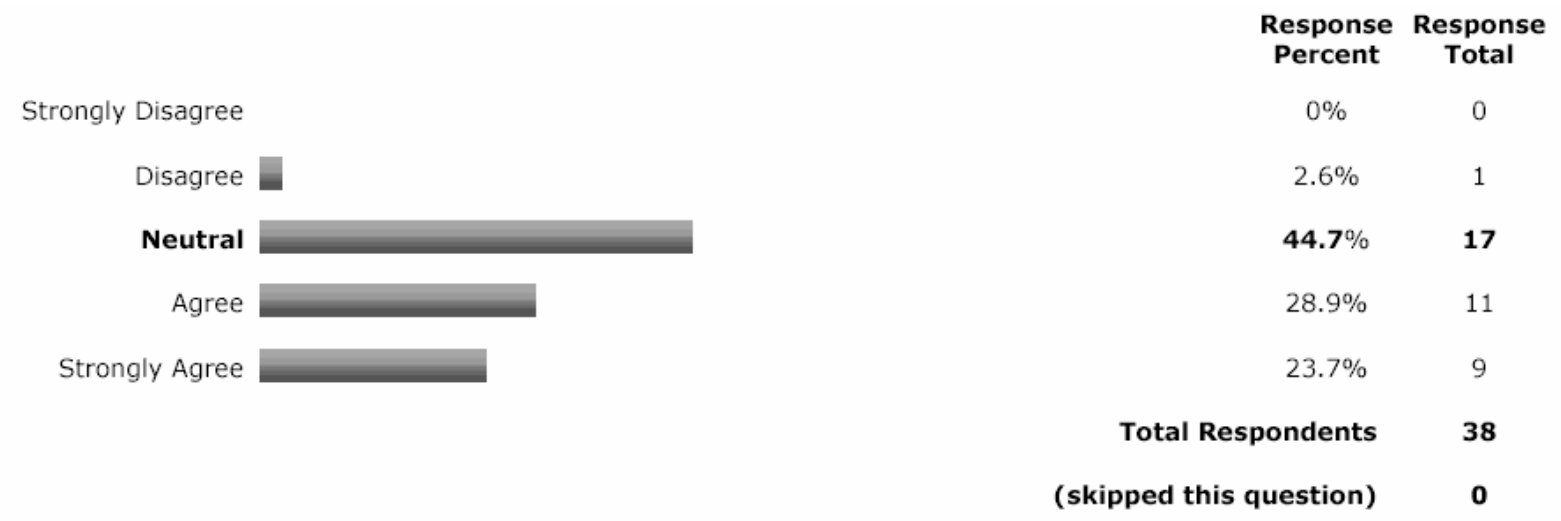

Figure 4. The course website has allowed you to access materials that the scheduling of your other classes would have prevented you from otherwise obtaining during a regularly scheduled class period of this course.

The fifth survey question (Figure 5) was designed to determine whether students responding to the survey were able to access materials from the course website that they would not have accessed when they were actually present in class. It should be noted that not all materials accessible from the website were offered in the form of printed handouts during regular class periods. Materials requiring less printing, such as the course outline and syllabus for each course, were generally made available to students in class, while materials of a more paper-intensive nature, such as lecture notes and supplements, were made available on request. In-class requests for these printed materials decreased throughout the two-semester study period. 


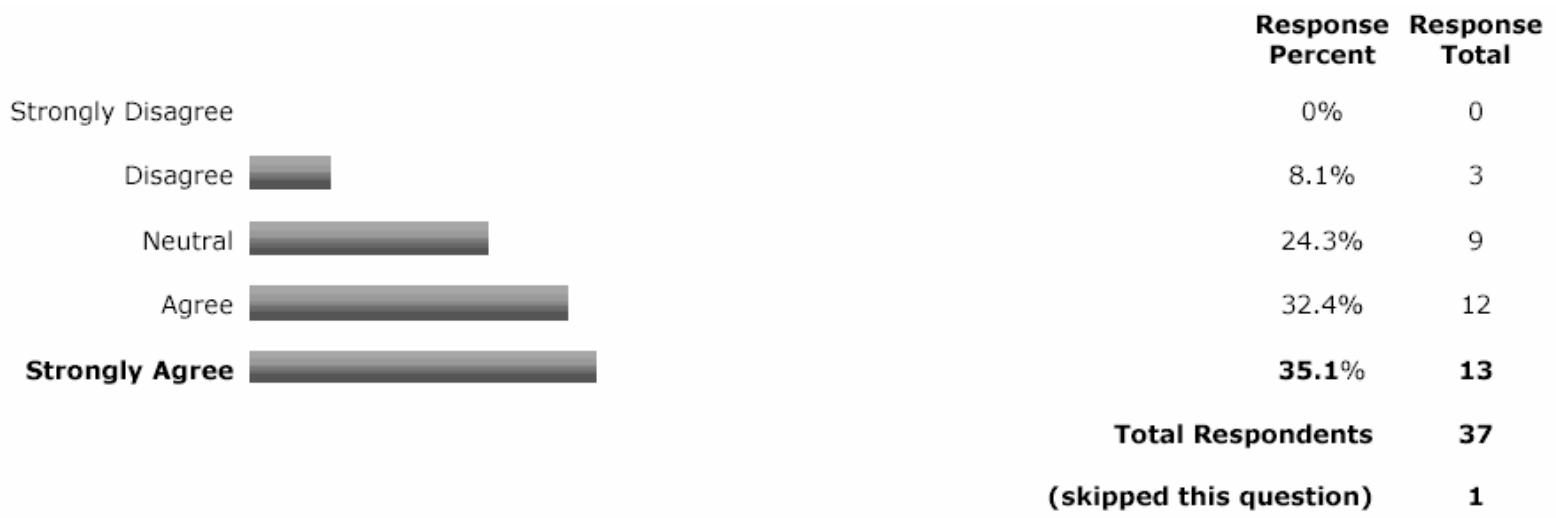

Figure 5. The course website has given you the opportunity to access materials that you would not have otherwise accessed during regular classes when you were present.

The sixth question (Figure 6), the last of the questions of the five-choice Likert response type, was designed to elicit a comparative judgment of the overall convenience afforded the student through the use of the course

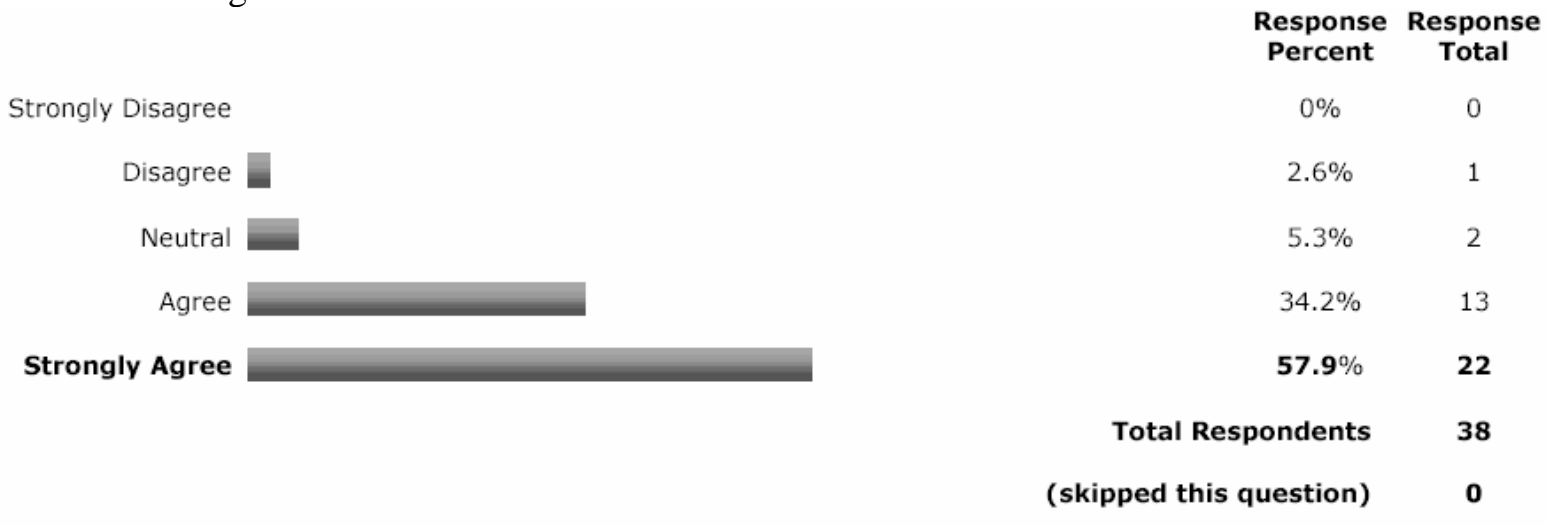

website. A majority of the respondents strongly agreed that their learning experience had been made more convenient with the hybrid delivery system, compared with traditional-style courses.

Figure 6. Compared with other courses that do not offer course websites, this course and its associated website have made your learning experience more convenient.

The remaining four questions were designed to allow the assessment of demographic information and the degree of nontraditionalism of the survey respondents. The Indianapolis campus of Purdue University's Statewide

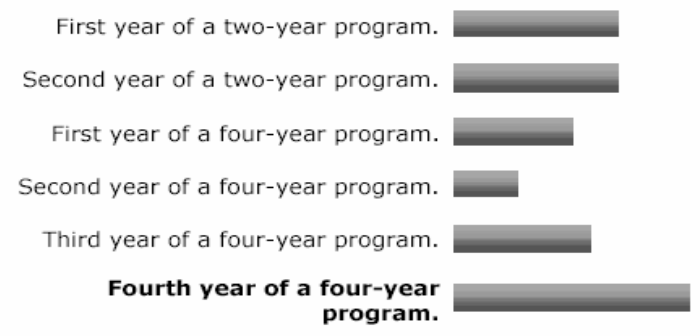

Figure 7. Please select your class level.
College of Technology provides both two-year and four-year degree programs, and the resulting distribution of the class levels of the respondents was fairly uniform (Figure 7). 
Percentage of full-time employment of the survey respondents was then determined. According to the results, the majority (55.3 percent) of students were employed between 30 and 40 hours per week (Figure 8). This implies that these students are, are least, minimally nontraditional or nearly so.

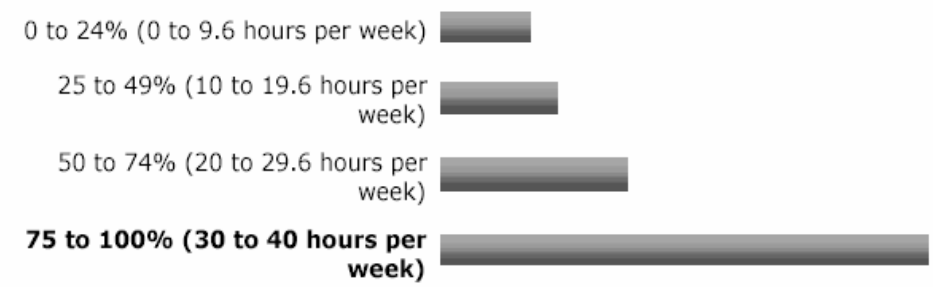

week)

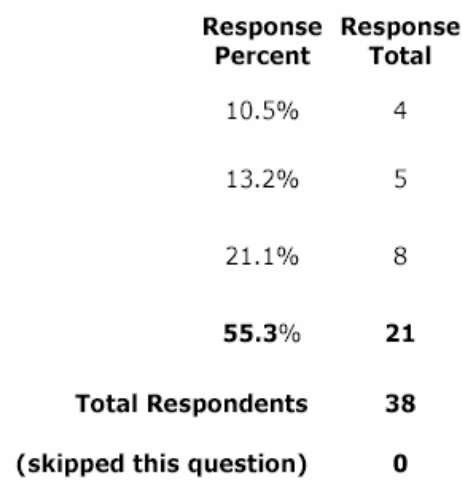

Figure 8. Please select the percentage of time that you are employed.

The next question allowed the determination of the enrollment status (full-time or part-time) of the participants. Five distinct credit hour enrollment categories were created, as shown in Figure 9. Note that, while a 12 hour credit load is considered full-time at Purdue University, it was desired to provide an enrollment category that would indicate the nearness of a part-time student to full-time status, and vice versa, without creating an excessive number of discrete choices, hence the inclusion of the 10 to 14 hour category. The

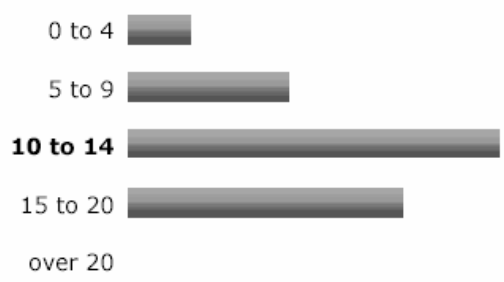

survey results indicate that at least 26.3 percent of the respondents were enrolled part-time, and therefore can be considered at least minimally nontraditional. A plurality of respondents, 42.1 percent, were taking from ten to fourteen credit hours, classifying them as either marginally parttime or marginally full-time, depending on the particular programs in which they were enrolled. Finally, 31.6 percent of the respondents could be considered strictly full-time, as they were enrolled for at least fifteen credit hours.

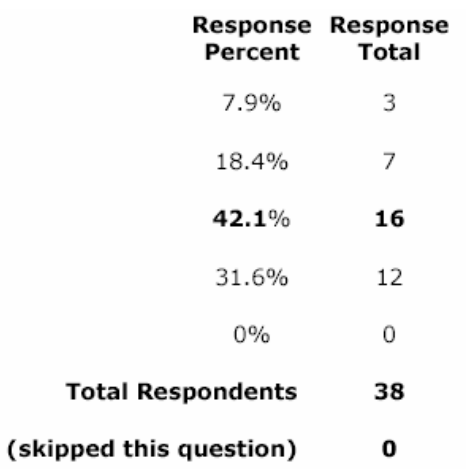

Figure 9. Please select the number of credit hours you were taking during the semester you were enrolled in this class.

In order to determine the amount of time respondents actually spent on campus, the last question in the survey was included (Figure 10). The results show that the hours per week spent on campus by the respondents were somewhat evenly distributed up to around 12 hours, with 94.7 percent indicating that more time was spent than that required for attendance of a single three credit hour class. 

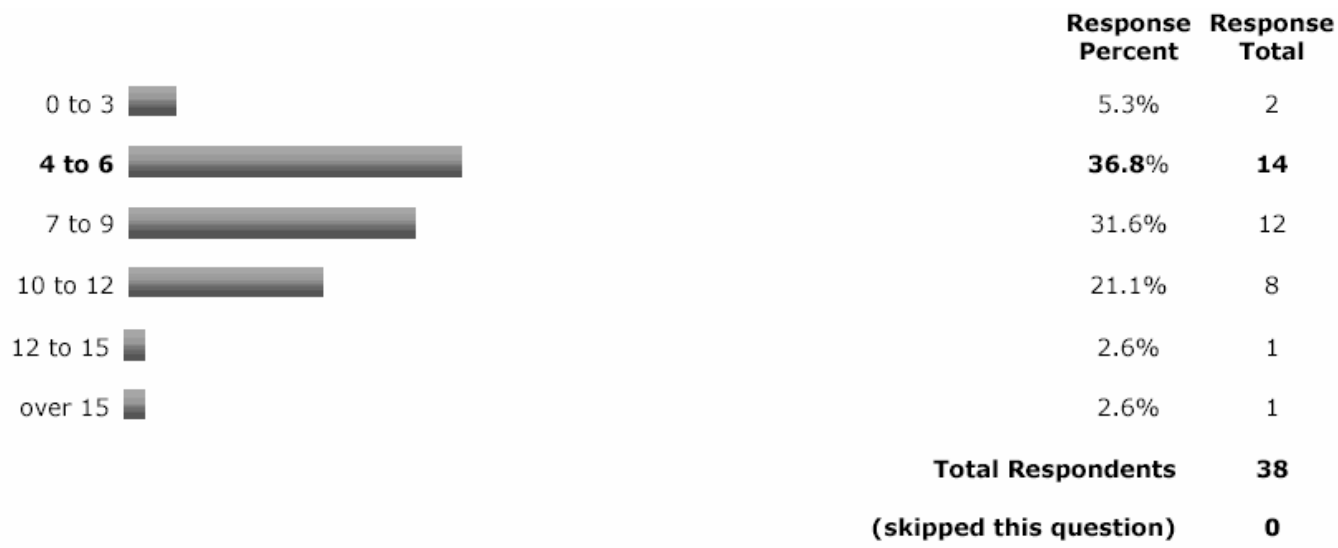

Figure 10. Please select the number of hours per week you spend on the Aviation Technology Center campus.

\section{ANALYSIS}

It is clear from the analysis of the first two survey questions that the course websites involved in this study were perceived by the majority of participating students to be helpful in making access to both course information and course materials more convenient. The apparent success of this hybrid delivery model, from a perspective of convenience of access, affirms the findings by Rivera, et al (2002).

One may hypothesize that, among those students whose class schedules are affected by their work schedules, some additional encroachment by work scheduling requirements upon scheduled classes exists, and the research conducted in this study supports that hypothesis. It might also be supposed that, in cases where scheduling conflicts have had an effect on the student's decision to take a certain section of a particular course and where time between classes at physically separate campuses is minimal, additional reductions in the degree of that student's availability for class have occurred, and that supposition is supported by this study, as well.

While it appears that conflicts between scheduling of classes were somewhat involved in reducing the time that the participants had available for class and thus were factors in making web access to course information and materials important, the instrumental factors in this regard were conflicts due to work schedules. It is interesting to examine the correlation between the responses to the questions related to perceived convenience and the responses to the questions involving class and work scheduling conflicts. Accordingly, the Pearson productmoment correlation coefficient (Hogg \& Craig, 1978; Cohen, et al, 2003) was calculated for these particular datasets. The Pearson correlation between the variable related to convenience of access of course materials (Question 1), the more strongly correlated of the two noncomparative convenience variables, and the work schedule variable (Question 3), was found to be 0.393 . The Pearson correlation between the former variable and the class schedule variable (Question 4) was determined to be 0.320 . Both of these coefficients indicate a weak positive correlation between the variables in question.

It is also useful to examine the correlation between the work schedule variable and the variable related to the percentage of full-time employment of the respondents (Question 8). That correlation coefficient was determined to be 0.098 , indicating no significant correlation between the variables. This indicates that the degree of convenience perceived by respondents accessing course materials through the website because of inconvenient work schedules does not necessarily depend on the number of hours per week that those respondents are employed.

Finally, as a check to verify the validity of the responses received, correlations between the number of credit hours for which the students were enrolled, the percentage of time employed, and the amount of time per week spent on campus by the students were examined. As one might expect, a moderate positive correlation (0.411) exists between the number of credit 
hours for which students were enrolled and the amount of time spent on campus, while a weak negative correlation $(-0.120)$ exists between the percentage of time employed and the amount of time spent on campus. It is also interesting to note the inverse relationship that exists between the number of students taking more than ten credit hours (28 students, from Figure 9) and the number of students who report being on campus for more than ten hours per week (10 students, from Figure 10). Possible explanations for this relationship are that some students were enrolled in either hybrid or fully online courses, or that students were simply absent from classes a portion of the time due to the class and work scheduling conflicts discussed above, or to other reasons.

\section{CONCLUSION}

As the postsecondary educational system progresses through a series of changes from the traditional course offering to the online offering, a hybrid method of instructional delivery that combines elements of each is a viable option. It was demonstrated that the aviation students participating in this study perceived that their learning experience was made more convenient through the use of such a hybrid delivery method involving a course website for better access to course information and materials. It was also demonstrated that the majority of the students participating in the study were at least minimally nontraditional. As the technological landscape grows and improves, it is expected that the delivery of exclusively online courses will proliferate. At the present time, however, the hybrid delivery model as described herein appears to provide an effective solution to the problem of course materials access by nontraditional students whose time and class attendance is constrained by work and scheduling issues. 


\section{REFERENCES}

Cohen, J., Cohen P., West, S.G., \& Aiken, L.S. (2003). Applied multiple regression/correlation analysis for the behavioral sciences. ( $3^{\text {rd }}$ ed.) Hillsdale, NJ: Lawrence Erlbaum Associates.

Davis, F. D., Bagozzi, R. P. \& Warshaw, P. R. (1989). User Acceptance of Computer Technology: A Comparison of Two Theoretical Models. Management Science, 35(8), 982-1002.

Dutton, J., Dutton, M., \& Perry, J. (2002). How Do Online Students Differ From Lecture Students? Journal of Asynchronous Learning Networks [Online], 6(1). Retrieved May 10, 2007 from http://www.sloan-c.org/publications/jaln/v6n1/v6n1_dutton.asp.

Ehrmann, S. C. (n.d.). Technology Changes Quickly but Education Changes Slowly: A Counter-intuitive Strategy for Using IT to Improve the Outcomes of Higher Education. Retrieved March 28, 2008, from http://www.tltgroup.org/resources/Visions/Outcomes.html.

Hogg, R.V., \& Craig, A.T. (1978). Introduction to Mathematical Statistics. New York: Macmillan.

Horn, L. (1996). Nontraditional Undergraduates, Trends in Enrollment From 1986 to 1992 and Persistence and Attainment Among 1989-90 Beginning Postsecondary Students (NCES 97-578). U.S. Department of Education, NCES. Washington, DC: U.S. Government Printing Office.

National Center for Education Statistics (2002). Special Analysis 2002 - Nontraditional Undergraduates. Retrieved May 15, 2007 from http://www.nces.ed.gov.

Twigg, C. A. (2003). Improving Learning and Reducing Costs: New Models for Online Learning. EDUCASE Review, 38(5), 28-38.

Rivera, J., McAlister, M., \& Rice, M. (2002). A Comparison of Student Outcomes and Satisfaction Between Traditional and Web Based Course Offerings. Online Journal of Distance Learning Administration [Online], 5(3). Retrieved May 12, 2007 from http://www.westga.edu/ distance/ojdla/fall53/rivera53.html.

Selim, H. M. (2005). An Empirical Investigation of Student Acceptance of Course Websites. Computers and Education, 40(4), 343-360. 